\title{
Dry Eye Disease: Consideration for Women's Health
}

\author{
Cynthia Matossian, MD, FACS, ${ }^{1}$ Marguerite McDonald, MD, FACS, ${ }^{2}$ Kendall E. Donaldson, MD, MS, ${ }^{3}$ \\ Kelly K. Nichols, OD, MPH, PhD, ${ }^{4}$ Sarah Maclver, OD, ${ }^{5}$ and Preeya K. Gupta, MD ${ }^{6}$
}

\begin{abstract}
Dry eye disease (DED) is a multifactorial disorder of the ocular surface and tear homeostasis that can result in discomfort, pain, and visual disturbance. Untreated, DED can become chronic, progressive, and significantly affect an individual's quality of life. Women are disproportionately affected by DED, are diagnosed at a younger age, and experience more severe symptoms compared with men. DED is associated with a wide range of comorbid conditions; there is a strong association between DED and autoimmune disorders, especially those that affect women at many times the rate of men. Treatment response questionnaires indicate women respond better to a wellness model of treatment for DED than men. Furthermore, women's health care-seeking behaviors provide opportunities for general practitioners, specialists, and women's health centers to help identify women with DED or at risk for DED for referral to an eye care specialist. This review of the prevalence of DED in women, and gender and sex-specific aspects of DED, highlight a significant opportunity for action. Earlier diagnosis and treatment of this common but burdensome condition could significantly improve a woman's quality of life.
\end{abstract}

Keywords: epidemiology, postmenopausal women, primary care, dry eye disease, autoimmune disease, comorbid conditions, quality of life, chronic, progressive

\section{Introduction}

D RY EYE DISEASE (DED) is an ocular disorder that is often characterized by symptoms of eye dryness, discomfort, and sensitivity to light. ${ }^{1,2}$ It is highly prevalent, increases with age and, as is the case with many ocular conditions, disproportionately affects women. ${ }^{3-11}$ Untreated, DED may become chronic and progressive and can significantly affect one's quality of life. $7,12-18$

Greater utilization of the health care system by women provides the opportunity for DED to be recognized and diagnosed earlier. ${ }^{12,19}$ Furthermore, women's health care settings, which are designed to offer "one-stop shopping" for medical needs compared with general internal medicine practices, and primarily utilized by younger individuals, ${ }^{20}$ may provide additional opportunities to identify, study, educate, and treat women with DED or at risk of developing DED. However, the literature on DED currently lacks a comprehensive review of the interrelationship of DED with women's health. Such a review could be used by clinicians outside of eye care, in addition to ophthalmologists and optometrists, to identify women with DED, or at higher risk of developing DED.

DED is a multifactorial disease, with a highly variable presentation in both clinical signs and patient-reported symptoms, making it difficult for clinicians outside of eye care to recognize. ${ }^{21-23}$ There are many symptoms other than "dryness" that are associated with dry eye that clinicians might not know, for example, blurred vision. However, a growing body of research investigating the root pathology of

\footnotetext{
${ }^{1}$ Matossian Eye Associates, Pennington and Pennington, New Jersey.

${ }^{2}$ Ophthalmic Consultants of Long Island, Lynbrook, New York.

${ }^{3}$ Department of Ophthalmology, Bascom Palmer Eye Institute, University of Miami Miller School of Medicine, Miami, Florida.

${ }^{4}$ School of Optometry, University of Alabama at Birmingham, Birmingham, Alabama.

${ }^{5}$ School of Optometry and Vision Science, University of Waterloo, Ontario, Canada.

${ }^{6}$ Division of Cornea and Refractive Surgery, Department of Ophthalmology, Duke University Eye Center, Durham, North Carolina.
}

(C) Cynthia Matossian et al. 2019; Published by Mary Ann Liebert, Inc. This Open Access article is distributed under the terms of the Creative Commons License (http://creativecommons.org/licenses/by/4.0), which permits unrestricted use, distribution, and reproduction in any medium, provided the original work is properly cited. 
DED, namely dysregulation of the ocular surface, including the ocular surface immune response, has led to greater understanding of the risk factors associated with DED. ${ }^{10,24-31}$ With these advances, it may be easier for non-eye care professionals to identify possible DED from risk factors, such as chronic illnesses and autoimmune diseases, combined with symptoms of ocular discomfort or visual disturbance.

We performed a nonsystematic literature search on topics focusing on the pathophysiology of DED and key epidemiology studies that have assessed differences in DED prevalence. Published studies discussed in this review include data according to self-reported gender (woman or man; e.g., surveys) or biological sex (female or male; e.g., hormonal studies). We explore the biological sex and hormonal differences in ocular structure, functioning, and health that contribute to the higher DED prevalence in women. We recapitulate the presenting signs and symptoms of DED that differ between women and men, and summarize some of the current research on DED-associated comorbidities that are more prevalent in, or specific to, women.

There is a high prevalence of DED in several Asian populations. ${ }^{6}$ However, when the data are stratified by gender, distribution of the disease is similar to studies in primarily Caucasian populations irrespective of ethnicity. ${ }^{32}$ In this review, we do not discuss the relationship between ethnicity and DED.

It is our hope that this review reaches a broad audience of health care professionals, with the goal of contributing to well-informed decisions for patient care strategies that do not increase the risk of DED or exacerbate current symptoms of DED in their patients. A better understanding of the risk factors and recognition of signs and symptoms of DED may facilitate and expedite referrals to an eye care professional. Furthermore, we envision a wide-ranging partnership between health care providers across the health care spectrum and eye care professionals that diagnose and/or treat patients with DED that can foster a more interdisciplinary approach to recommending preventative measures and treatments.

\section{Definition and Pathophysiology of DED}

Tears help to maintain the health of the ocular surface in addition to providing a smooth, refractive surface for optimal vision. ${ }^{33,34}$ Tears form a multilayered gradient fluid film over the ocular surface that helps to protect the cornea and lubricate blinking mechanics. The most superficial layer is a lipid layer that is deposited by small glands, called meibomian glands (MGs), lining the upper and lower eyelids during the blinking process and seals the tear film to reduce tear evaporation. The middle aqueous layer, composed of water, soluble mucins, and other proteins, constitutes $90 \%$ of the tear film volume and enables tear spreading ${ }^{34,35}$; this layer is secreted by the lacrimal and accessory lacrimal glands. The innermost mucous layer, made up of membrane-adherent mucins, interacts directly with the corneal epithelial cells. ${ }^{34,35}$

In healthy eyes, homeostasis of the tear film layers and their components is maintained within a very narrow, yet stable range. ${ }^{34}$ The homeostasis of the tear film, or loss thereof, can be assessed by measuring its osmolarity, which is more generically defined as the extent of solute particles in a solution. $^{36}$ Tear film hyperosmolarity is, therefore, an increased amount of solute particles per tear film volume, and can result from reduced tear volume or increased tear evaporation. ${ }^{33,34}$
A central factor in the pathogenesis of DED is the loss of tear film stability, which usually results in hyperosmolarity, and leads to or may exacerbate damage to the ocular surface. ${ }^{1,2,33,34}$ Hyperosmolarity can result in symptoms of ocular discomfort, dryness, and/or vision disturbances. However, DED can also be present, as assessed by multiple clinical signs, in asymptomatic individuals. The chronic and sometimes progressive nature of DED is believed to be initiated by multiple factors that are self-perpetuated by an inflammatory cascade that causes further damage to the ocular surface. ${ }^{33}$ This, in turn, increases the inflammatory response and perpetuates a cycle of increased osmolarity and ocular surface damage. This "vicious circle" of DED can be complicated by a variety of lid and ocular surface diseases that further aggravate and damage the ocular surface. ${ }^{13}$

Hyperosmolarity of the tear film can result from reduced tear volume or increased tear evaporation. ${ }^{33,34}$ Aqueous deficient dry eye (ADDE) is defined by the presence of normal evaporation with a reduced tear volume and is the primary cause of DED in individuals with lacrimal gland dysfunction, such as in Sjögren's syndrome, rheumatoid arthritis (RA), diabetes mellitus, and age-related dry eye. Evaporative dry eye (EDE) is characterized by a normal tear volume with an increased rate of tear evaporation. EDE is the primary cause of DED in MG dysfunction and atrophy, and also is associated with Sjögren's syndrome. ${ }^{1}$ While there are two main types of DED defined, people with DED tend to fall within a spectrum of aqueous deficiency and evaporative disease, and often have signs of both present. ${ }^{1}$

\section{Epidemiology of DED}

The epidemiology of DED has been increasingly studied since the publication of the 2007 Dry Eye Disease Workshop (DEWS) report, ${ }^{2}$ an encyclopedic review of the current state of DED knowledge and research. It was used to identify future research efforts needed to improve the understanding of the etiology and pathogenesis of DED to facilitate development of potential therapies. However, a central difficulty in these efforts has been establishing the criteria for diagnosis of DED.

Criteria for diagnosing DED vary considerably across epidemiological studies because of high variability in the clinical presentation and numerous causes and/or complicating factors of DED. A diagnosis of DED is based on self-reported signs and symptoms in response to standardized questionnaires on ocular discomfort (physical sensation, intensity, and frequency) and clinical tests (e.g., corneal staining and measures of tear break-up time). For comparisons across epidemiological studies using similar or the same criteria for diagnosis of DED, and where the prevalence and incidence of DED in population-based studies has been stratified by gender and age, it has been consistently found that DED increases with age and disproportionately affects women. ${ }^{3-7,9-11,37,38}$

A meta-analysis of recent DED prevalence studies conducted by the 2017 TFOS DEWS II researchers found increases in the prevalence of DED signs and symptoms per decade starting at ages 40-49 years. ${ }^{11}$ For women, the prevalence of DED symptoms starts increasing from $14 \%$ at 50 years of age to $22 \%$ for those $80+$ years of age. This trend is both less prominent and starts later for men, with a prevalence of DED symptoms increasing from 7\% in men 60-69 years of age to $13 \%$ for those $80+$ years of age. 
Two large studies of DED prevalence conducted in the United States using the same criteria for DED diagnosis, the 2003 Women's Health Study (WHS; $n=39,000$ females, ages 49+ years) and the 2009 Physicians' Health Study (PHS; $n=25,000$ males, ages $50+$ years), were used to draw comparisons of DED between genders and across ages. ${ }^{6,12,39}$ The studies found that the mean age of patients at diagnosis of their DED was 60 years for women versus 66 years for men. Ocular Surface Disease Index (OSDI) ${ }^{40}$ and the Symptom Assessment in Dry Eye (SANDE) ${ }^{41}$ are two of several validated dry eye questionnaires; evaluation using these questionnaires showed that severe symptoms were more common in women. ${ }^{6}$ Prevalence values from these studies were used to estimate DED prevalence in the United States population at nearly twice as high for women (3.25 million) as men (1.68 million). ${ }^{6,12,39}$

Table 1 summarizes recent DED studies from the United States that stratify DED prevalence and associated signs and symptoms by sex and/or gender. All of the studies generally support that major DED risk factors include female sex and age. The Beaver Dam Offspring Study (BOSS, 2014) found that prevalence in women was $17.9 \%$ versus $10.5 \%$ in men and that hormone therapy (HT) in women was an additional risk factor for DED. ${ }^{7}$

An analysis of data from the United States National Health and Wellness Survey (NHWS, 2017) found that gender differences in the prevalence of DED increased with age. ${ }^{32}$ While the prevalence of DED was nominally higher for women versus men in younger years (age 18-34 years: $2.9 \%$ vs. $2.6 \%$ ), this difference increased significantly for older respondents (age $\geq 75$ years: $22.8 \%$ vs. $12.6 \%$ ).

Bradley et al. reported on a study of the United States Department of Defense (DoD) Military Health System (MHS) claims database analysis (2017), which covers over 9.7 million active military duty and retiree beneficiaries and their dependents from ages 2-80+ years. ${ }^{42}$ MHS data analysis revealed higher prevalence of DED in women (7.8\% vs. $3.0 \%$ in men), and increases with age (18-39 years: $3.1 \%$ vs. $1.3 \%$; $\geq 50$ years: $15.9 \%$ vs. $7.0 \%)^{42}$

These differences in DED prevalence between women and men fall in the domain of gender effects on health. In addition to differences in metabolism, lifestyle, and physical performance, this rich field of study has identified sex differences in response to therapeutic agents, diagnostic and therapeutic interventions, sex differences in autoimmune conditions, and a spectrum of sex differences across common diseases such as coronary heart disease. ${ }^{43}$ DED prevalence differences are attributed to biological sex, hormonal, and gender differences, which contribute to DED risk factors, presentation, immune response, pain experience, and treatment response that are specific to women. Fortunately, there are differences in women's health care-seeking behaviors and health care service utilization, which will be discussed later, that provide opportunities for earlier referral and diagnosis of DED. ${ }^{19}$

\section{Biological Sex and Hormonal Differences in Ocular Structure, Functioning, and Health}

Biological sex differences that affect ocular structure, functioning, and health are noted from the molecular level to the physiological observational level. Molecular-level differences include differences in tissue morphology, gene expression, protein synthesis, and epithelial cell dynamics. ${ }^{10}$ These molecular-level differences translate to differences in aqueous tear output, lipid production, mucous secretion, tear film stability, blink rate, and ocular immune functioning, which, when pathologic, may contribute to DED signs and symptoms.

For example, the transglutaminase 1 (TGase1) gene, which catalyzes protein crosslinking and thus plays a role in keratinization mechanisms, has greater expression in the healthy female cornea than the healthy male cornea by about $2: 1$. $^{44}$ An in vivo vitamin A deficiency model of dry eye showed that TGase 1 transcript and protein levels increased with time and disease severity. ${ }^{45}$ Pathologic keratinization of the cornea and conjunctival epithelium in patients with severe chronic dry eye, such as that associated with Sjögren's Syndrome and Stevens-Johnson syndrome, is accompanied by upregulation of TGase 1. ${ }^{46-48}$ It has been hypothesized that the increased expression of TGase 1 in women, when combined with differentiated levels of other important ocular sex steroids (androgens and estrogens), could be a contributing factor in the increased prevalence of DED in women. ${ }^{44}$

Hormonal differences between men and women, including both basal and lifespan-associated levels of sex steroids (androgens and estrogens), as well as hormonal cycles specific to the female sex (menstruation, pregnancy, menopause), also affect ocular structure, functioning, and health. Studies of associations of DED and sex steroid levels (testosterone, 4androstene-3, 17-dione, estrogen, estrone, 17- $\beta$-estradiol, progesterone, and $17 \alpha$-hydroxyprogesterone) have produced a variety of results regarding the levels of many sex steroids, especially estrogen, and their association with DED. ${ }^{10,49-53}$

Table 1. Dry Eye Disease Prevalence From United States Studies

\begin{tabular}{|c|c|c|c|c|c|c|c|c|}
\hline Study & Type & $\begin{array}{c}\text { Years } \\
\text { conducted }\end{array}$ & $\mathrm{N}$ & $\begin{array}{c}\text { Age range } \\
\text { (years) }\end{array}$ & $\begin{array}{c}\text { Female } \\
(\%)\end{array}$ & $\begin{array}{c}\text { DED } \\
\text { prevalence } \\
\text { overall }(\%)\end{array}$ & $\begin{array}{c}D E D \\
\text { prevalence } \\
\text { in females }(\%)\end{array}$ & $\begin{array}{l}D E D \\
\text { ratio } \\
F / M\end{array}$ \\
\hline $\mathrm{WHS}^{12}$ & Population & $1992+$ & 36,995 & $49-89$ & 100.0 & 7.8 & 7.8 & $1.8^{\mathrm{a}}$ \\
\hline $\mathrm{PHS}^{39}$ & Population & $1982+$ & 25,444 & $50-99$ & 0.0 & 4.3 & N/A & $1.8^{\mathrm{a}}$ \\
\hline $\mathrm{BOSS}^{7}$ & Population & 2005-2008 & 3,285 & $21-84$ & 54.6 & 14.5 & 17.9 & 1.7 \\
\hline $\mathrm{NHWS}^{32}$ & Population & 2013 & 75,000 & $18-49$ & 50.4 & 8.8 & 4.5 & 2.0 \\
\hline $\begin{array}{l}\text { DoD } \\
\text { MHS }^{127}\end{array}$ & $\begin{array}{l}\text { Retrospective } \\
\text { database analysis }\end{array}$ & 2003-2015 & $9,732,272$ & 2-90+ & 48.1 & 5.3 & 7.8 & 2.6 \\
\hline
\end{tabular}

${ }^{\text {a}}$ Ratio of female to male (F/M) refers to the Women's Health Study/Physician's Health Study (WHS/PHS).

BOSS, Beaver Dam Offspring Study; DED, dry eye disease; DoD, Department of Defense; MHS, Military Health System; N/A, not applicable; NHWS, National Health and Wellness Survey. 
Among these, low androgen levels are most consistently associated with DED. ${ }^{51}$ Sex steroids can be assessed systemically, by sampling of blood serum levels, or locally, by quantification of their presence in tears or ocular tissues. ${ }^{53}$ The associations of sex steroids to ocular diseases and DED have yet to be fully determined, but consensus holds that their influence on ocular surface conditions should be considered.

The association between DED and both systemic and ocular testosterone levels in women has yielded conflicting and/or inconclusive results. Blood serum levels of testosterone in postmenopausal women were assessed against corresponding OSDI scores in a small study between those with mild-tomoderate DED $(n=15)$, those with severe dry eye $(n=4)$, and women with no dry eye $(n=5),{ }^{49}$ revealing no significant relationship between the two. In a study of 44 postmenopausal women, half with severe $\operatorname{EDE}(n=22)$ and half without $(n=22)$, profiles of fasting blood serum levels of $17-\beta$ estradiol, estrone, and total testosterone were compared with results from detailed eye examinations. The levels of $17-\beta-$ estradiol, estrone, and total testosterone in women with severe EDE showed inverse correlations to tear film osmolarity (regression coefficient, $r=-0.7,-0.88$, and -0.81 , respectively). ${ }^{50}$

A method of steroid profiling in tear fluid was first published by Pieragostino et al. (simultaneous quantification of cortisol, corticosterone, 11-deoxycortisol, 4-androstene-3,17dione, testosterone, $17 \alpha$-hydroxyprogesterone, and progesterone levels). ${ }^{53}$ These steroids were extracted from tears collected on a Schirmer strip, followed by subsequent analysis by high-performance liquid chromatography/tandem mass spectrometry. This method was used in an analysis of tear samples from 14 females with DED and 13 healthy female controls, which found significant decreases in cortisol, 4androstene-3,17-dione, and 17 $\alpha$-hydroxyprogesterone levels for patients with dry eye compared with controls. ${ }^{53}$

In a separate study, venous blood sampling and meibography were used to evaluate the association between serum levels of testosterone and estradiol and MG morphology in postmenopausal women $(n=198$, average age 61.2 [ \pm 9.1$]$ years). ${ }^{52}$ MG dropout increased with higher testosterone levels, and a significant difference in testosterone levels was observed in the mild versus severe MG dropout groups (MG dropout scores of 1 and 4, respectively; $p=0.002$ ). Differences were not significant with estradiol and meibography assessments $(p=0.53)$.

Sex-associated differences in ocular physiology have been identified in the $\mathrm{MG},{ }^{54}$ lacrimal gland,${ }^{55}$ conjunctiva, ${ }^{56}$ and cornea,${ }^{8}$ as well as other eye structures (anterior chamber, ciliary body, iris, lens, retina, and vitreous). These physiological differences may contribute to the different DED prevalence rates observed in women and men. ${ }^{10}$ For example, sex-specific changes in the cornea occur during the menstrual cycle, pregnancy, and menopause, and include variations in thickness, hydration, curvature, sensitivity, and endothelial pigmentation, as well as contact lens tolerance and a higher prevalence of a loss of visual acuity. ${ }^{8}$

Some studies have suggested that changes in estrogen levels alter ocular surface equilibrium during the menstrual cycle, impacting subjective dry eye symptoms in female patients. ${ }^{57}$ In women with dry eye in particular, the estrogen peak (during the follicular phase) appears to be related to symptoms of impaired tear production and stability, surface dryness, and inflammation. ${ }^{58}$
Sex-related differences in the innate and adaptive immune responses of the ocular surface have been found to be mini$\mathrm{mal}$ in the absence of systemic diseases. ${ }^{59}$ However, the close association of DED and autoimmune diseases that disproportionately affect women may also suggest that ocular surface immunity differences between the sexes manifest when the immune system is challenged. ${ }^{10}$

\section{DED-Associated Comorbidities Burden and Autoimmune Diseases Primarily Affecting Women}

DED is comorbid with a wide range of conditions. In the NHWS analysis, the extent of this association with various comorbidities differed between symptomatic and asymptomatic DED as well as with sex (Fig. 1, Shire data on file). All respondent women in the study with thyroid disease or depression were at greater risk of symptomatic DED compared with men. The analysis was further stratified by age groups. For survey respondents $<65$ years, diabetes mellitus was an additional risk factor for symptomatic DED in women but not men, and for those $\geq 65$ years of age, headache/migraine or depression in the preceding 12 months were additional risk factors in women but not men. While headache, as a symptom, can be a very broad term-that is, not every patient with a headache is at risk for DED-older women who describe frequent or regular headaches/migraine that also have coexisting ocular symptoms may require a referral for possible DED.

In both age groups, men diagnosed with DED were at a higher risk of having glaucoma than women with any type of DED. Anxiety was a much higher risk for symptomatic DED in women $\geq 65$ years of age than for men. In the analysis of the WHS versus PHS studies, ${ }^{6}$ there was a significantly higher comorbid rate of Sjögren's syndrome, systemic lupus erythematosus (SLE), and rosacea in women. For men, higher comorbid rates of blepharitis and MG dysfunction were observed.

Autoimmune diseases are generally more prevalent in women than in men. ${ }^{60}$ Severe dry eye can be precipitated by several common autoimmune conditions in which inflammation plays a key role: Sjögren's syndrome, SLE, RA, and thyroid diseases. ${ }^{60}$ Although the link between rosacea and autoimmunity is still under debate, rosacea is a chronic inflammatory disease that is often associated with DED. 25,61,62 In these diseases, females represent the majority of cases (ratio of women:men) ${ }^{63}$; Sjögren's syndrome (9:1), SLE (7:1), RA (3:1), thyroid diseases (3.1-5:1), and rosacea (3:1) (Table 2).

In Sjögren's syndrome, a chronic inflammatory disorder, lymphocytic infiltration of the lacrimal glands precipitates ADDE. $^{21,64}$ In the lacrimal gland tissue of women with Sjögren's syndrome, androgen deficiency is both a sign and potentially a cause of the local steroidal imbalance precipitating lacrimal gland inflammation and ADDE. ${ }^{65}$ Further research is needed to understand the specific lacrimal and ocular surface mechanisms of EDE in relation to Sjögren's syndrome.

SLE is a chronic, multisystem, autoimmune disease, and DED is its most common ocular manifestation. ${ }^{25}$ Ocular symptoms can correlate with systemic disease progression, which may present before other systemic signs of SLE, underscoring the importance of ophthalmological examinations for SLE patients. ${ }^{66}$ Immune complex deposition in the lacrimal gland caused by SLE may result in secondary Sjögren's 
- DED Diagnosed vs. controls

- DED Symptomatic-undiagnosed vs. controls
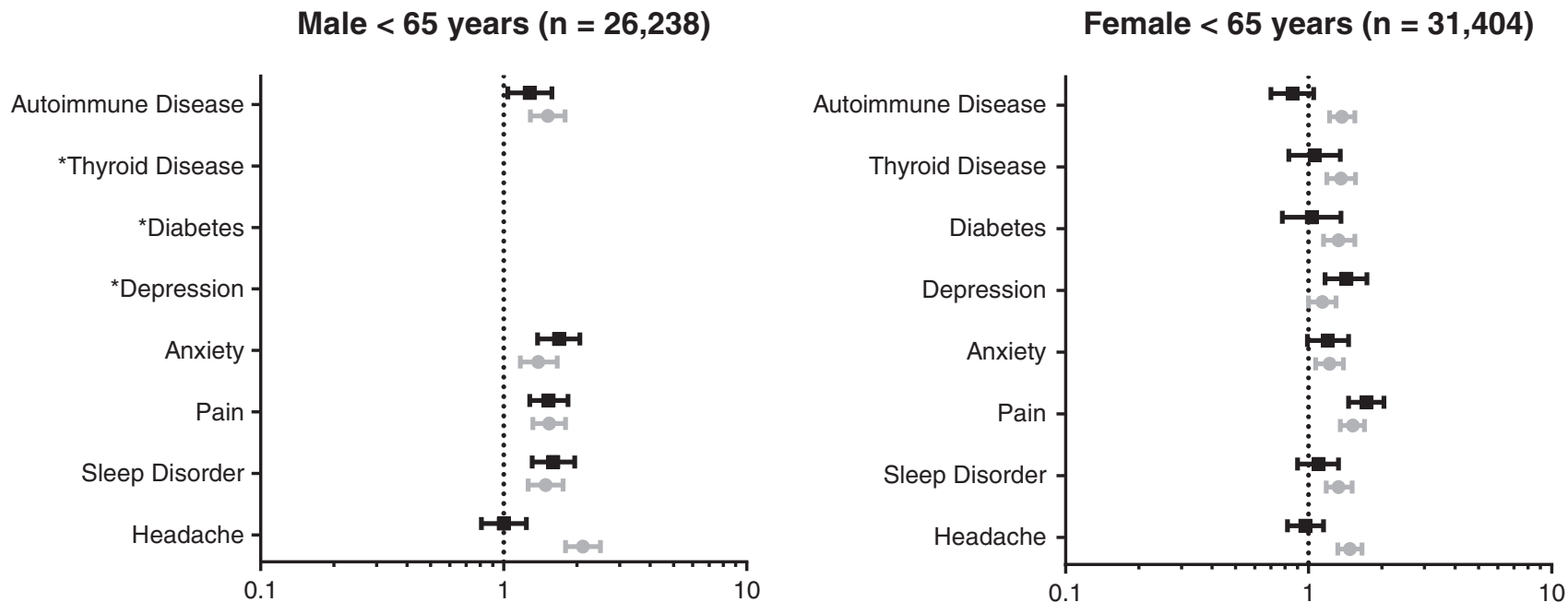

Male $\geq 65$ years $(n=9,499)$

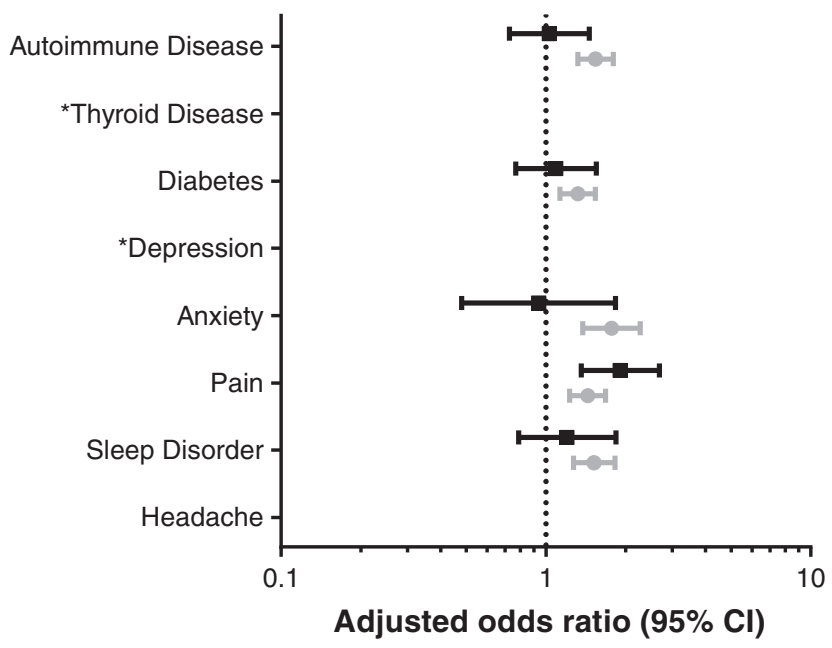

Female $\geq 65$ years $(n=6,909)$

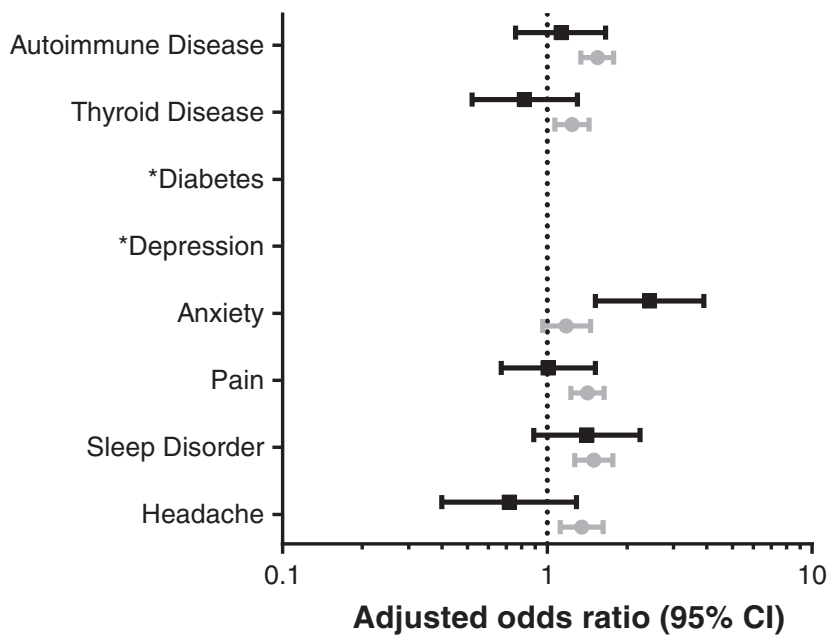

FIG. 1. Risk of DED by comorbidities of interest from NHWS Study. No data are shown for comorbid conditions where there was no significant association with DED status in the strata of interest. Shire data on file. CI, confidence interval; DED, dry eye disease; NHWS, National Health and Wellness Survey.

syndrome causing dry eye due to lack of adequate tear production (ADDE). Approximately $20 \%$ of SLE patients experience coexisting Sjögren's syndrome. ${ }^{67}$

RA is a chronic autoimmune inflammatory polyarthritis that causes irreversible synovial joint damage. ${ }^{25} \mathrm{ADDE}$ is the most common ophthalmic manifestation of RA. ${ }^{68}$ DED prevalence in RA patients is reported to be $15 \%-25 \% .{ }^{69} \mathrm{DED}$ in RA patients can be caused by the inflammatory effects of the disease, but DED may also manifest iatrogenically through treatment of the arthritis with corticosteroids and hydroxychloroquine. ${ }^{29}$ New categories of disease-modifying antirheumatic drugs that block the Janus kinase pathways in the immune response are available; however, their effect on ocular immune response, and their risk for development of DED, is not yet known. ${ }^{70,71}$

It is common for patients with rosacea to have ocular signs and symptoms. These can include blurred vision, photopho- bia, tearing, burning, irritation, foreign body sensation, and red eyes. ${ }^{25}$ Inflammation of the tissue around the MGs and subsequent alteration to the lipids produced by the glands is hypothesized to be a cause of the ocular manifestations in these patients and can lead to tear film abnormalities and EDE. Ocular rosacea also causes a reduction in tear volume in more than one-third of those with the ocular manifestation. ${ }^{72} \mathrm{~A}$ study was undertaken to compare the symptomatic relief from ocular complications of rosacea that could be obtained from treatment with topical cyclosporine ophthalmic emulsion $0.05 \%$ versus oral doxycycline, the reference treatment for ocular rosacea. The topical ophthalmic treatment was found to be more effective than the systemic medication more commonly prescribed for rosacea patients. ${ }^{73,74}$

Autoimmune thyroid eye disease, such as Hashimoto's thyroiditis or Graves' disease, is a disorder in which the ocular tissues are attacked and become inflamed. ${ }^{75}$ Women are 
Table 2. Autoimmune Diseases Associated with Dry Eye Disease ${ }^{63}$

\begin{tabular}{|c|c|c|}
\hline Autoimmune disease & $\begin{array}{c}\text { Ratio } \\
\text { women:men }\end{array}$ & DED association (DED type/manifestation) \\
\hline Rosacea & $3: 1$ & $\begin{array}{l}\text { Chronic, cutaneous inflammatory disease with ocular symptoms, including } \\
\text { foreign body sensation, burning, irritation, tearing, photophobia, blurred } \\
\text { vision, and red eye } \\
\text { Contributes to meibomian gland inflammation, dysfunction, and EDE }\end{array}$ \\
\hline Rheumatoid arthritis & $3: 1$ & $\begin{array}{l}\text { Ophthalmic manifestation of chronic inflammation-keratitis, MGD } \\
\text { (ADDE+EDE) }\end{array}$ \\
\hline $\begin{array}{l}\text { Hashimoto's thyroiditis; } \\
\text { Graves' disease }\end{array}$ & $3-5: 1 ; 7: 1$ & $\begin{array}{l}\text { T lymphocytes and autoantibodies directed against specific orbital or } \\
\text { thyroid-and-orbital shared antigen(s) causing thyroid eye disease (EDE) }\end{array}$ \\
\hline SLE & $7: 1$ & $\begin{array}{l}\text { Immune complex deposition in the lacrimal gland caused by SLE may } \\
\text { result in secondary Sjögren's syndrome causing dry eye due } \\
\text { to lack of adequate tear production (ADDE) }\end{array}$ \\
\hline Sjögren's syndrome & $9: 1$ & $\begin{array}{l}\text { Dry eye due to lack of adequate tear production and chronic inflammation } \\
\text { may lead to MGD (ADDE+EDE) }\end{array}$ \\
\hline
\end{tabular}

ADDE, aqueous deficient dry eye; EDE, evaporative dry eye; MGD, meibomian gland disease; SLE, systemic lupus erythematosus.

five to six times more likely than men to get thyroid eye disease. $^{76}$ It is believed that thyroid antibodies target eye muscles and connective tissue within the eye socket because these tissues contain proteins that appear similar to those of the thyroid gland. Dry eye and irritation in these patients are attributable to inflammation and swelling of tissue around the eye that causes incomplete blinking and an inability to shut the eyes. Thyroid eye disease must be treated as a separate ocular condition to the thyroid imbalance since systemic treatment of the thyroid gland does not consistently improve thyroid eye disease. ${ }^{76}$

\section{DED and Chronic Pain}

Associations have also been found between DED and chronic pain. ${ }^{18,23,77-80}$ Like DED, risk factors for many chronic pain syndromes (CPS) are female sex and older age. ${ }^{81,82}$ The higher incidence of pain-related symptoms among women with DED compared with men with DED suggests an underlying biological mechanism that may be sex related. ${ }^{10}$

In the Netherlands, a study of 425 patients with DED found that $17 \%$ of DED patients had at least one other CPS, such as chronic pelvic pain, fibromyalgia, or irritable bowel syndrome. ${ }^{82}$ When assessed by the OSDI symptom survey, DED patients with CPS had a mean OSDI score of 45.8, versus 33.8 in DED patients with no CPS. OSDI score is on a scale of $0-100$; normal range is $0-10$, clinical sensitivity for DED begins at an OSDI score of $\geq 13$, moderate DED 23-32, and severe DED $\geq 33$. ${ }^{40,83}$ Of 64 patients from the United Kingdom Twins Registry who were diagnosed with DED, 38\% (24/64) also had CPS and higher OSDI symptom scores compared with those with no CPS (OSDI score 34.1 vs. 14.4; $p=0.001)^{84}$

From a prospective, cross-sectional study of 40 DED patients with no other known systemic disease, age and gender matched to 20 patients with fibromyalgia and 20 healthy controls, $^{85}$ it was found that $62 \%$ of patients with fibromyalgia had DED based on OSDI scores. Ocular and visual symptoms self-reported from the OSDI and the National Eye Institute Visual Functioning Questionnaire (VFQ-25) were statistically higher in DED and fibromyalgia groups when compared with the control group $(p<0.0001)$.
Vehof and researchers from the Netherlands and the United Kingdom have hypothesized that the chronic pain in DED may be a neuropathic type of pain, persisting through nociceptive pathways. ${ }^{82}$ Clinical consequences of corneal damage activate an alarm system integrated in the peripheral and central trigeminal sensory network. Pathological elements in this response lead to a neuralgia that is characterized by a large disparity between intense pain symptoms and clinical signs correlating to those symptoms. ${ }^{79}$ They also found the severity of signs of DED had a lower correlation to symptoms in women compared with men $(\rho=0.11$ in women vs. $\rho=0.33$ in men; $p=0.01) .{ }^{86}$ The lack of concordance between symptoms and signs of DED has contributed to the lack of standardized diagnosis used across clinical studies. ${ }^{77,87,88}$

\section{latrogenic and Gender Differences That Increase DED Risk in Women}

We must also consider iatrogenic causes of DED and cultural behaviors specific to women that may increase the risks of DED. Iatrogenic causes include contact lens use; elective ophthalmic procedures, such as laser-assisted in situ keratomileusis (LASIK) for refractive error correction; periorbital surgeries to improve blinking mechanics or for cosmesis; and both systemic and topical medical treatments, such as hormone replacement therapies and allergy eye drops. ${ }^{59}$ Behavioral causes of DED include cosmetic periorbital surgeries and the use of permanent and topical cosmetics and facial creams. ${ }^{59}$ Some of the external causes of DED are listed in Table 3.

Two-thirds of the more than 45 million contact lens users in the United States are women. ${ }^{89,90}$ In some individuals, depending on the type of contact lens, long-term contact lens wear has been found to desensitize the cornea. ${ }^{91}$ In a large epidemiological study in Canada, contact lens use was found to increase the risk of experiencing DED symptoms. ${ }^{92}$ In a questionnaire-based study of contact lens wearers in the United States, ocular surface discomfort (scratchiness) was significantly higher for women than for men $(p<0.008) .{ }^{93}$ In addition, dryness and discomfort are the leading causes of contact lens discontinuation. ${ }^{94,95}$ In a recent study, contact lens use was found to accelerate age-related morphological 
Table 3. Iatrogenic Procedures and Dry Eye Disease

\begin{tabular}{|c|c|c|}
\hline $\begin{array}{l}\text { Iatrogenic and elective } \\
\text { causes of DED }\end{array}$ & Reason for procedure or use & DED causation \\
\hline Blepharoplasty & $\begin{array}{l}\text { Therapeutic or cosmetic } \\
\text { eyelid surgery }\end{array}$ & Incomplete blinking and exposure of ocular surface $99,101,128$ \\
\hline $\begin{array}{l}\text { Laser in situ } \\
\text { keratomileusis } \\
\text { (LASIK) }\end{array}$ & Refractive correction & $\begin{array}{l}\text { Alteration of corneal shape and/or neural feedback } \\
\text { loop dysregulation } 59,129-131\end{array}$ \\
\hline $\begin{array}{l}\text { Botulinum toxin type A } \\
\text { injections (BTX-A) }\end{array}$ & $\begin{array}{l}\text { Therapeutic or cosmetic } \\
\text { site-specific muscle block }\end{array}$ & Incomplete blinking and exposure of ocular surface 59,104 \\
\hline Contact lenses & Vision correction & $\begin{array}{l}\text { Reduced oxygen and increased friction to ocular } \\
\text { surface }\end{array}$ \\
\hline Prescribed medications & $\begin{array}{l}\text { Oral and ophthalmic topical, } \\
\text { therapeutic for other } \\
\text { conditions }\end{array}$ & $\begin{array}{l}\text { Secondary dryness effects related to medication use, } \\
\text { preservatives in ophthalmic topical } \\
\text { treatments } 5,7,17,59,107,133-135\end{array}$ \\
\hline $\begin{array}{l}\text { Permanent eye } \\
\text { cosmetics (tattoos) }\end{array}$ & Cosmetic & Destruction of meibomian glands ${ }^{59,105}$ \\
\hline $\begin{array}{l}\text { Topical cosmetics } \\
\text { and facial creams }\end{array}$ & Cosmetic and protective & $\begin{array}{l}\text { Increased debris on corneal surface, retinoids and oils } \\
\text { from periorbital application of creams may cause } \\
\text { meibomian gland atrophy }\end{array}$ \\
\hline
\end{tabular}

changes in MGs, such as MG dropout, which may be associated with DED. ${ }^{96}$

LASIK is a procedure performed for the surgical correction of refractive error. In the United States, LASIK has been performed in over 21 million patients as of $2015 .{ }^{97}$ LASIK may increase the risk for DED, particularly in women. ${ }^{97,98}$ Data from the UK Biobank Study found that LASIK procedures were performed more often in women than in men, although the incidence of this procedure and the gender difference decreased with age. ${ }^{97}$ A 1 -year retrospective analysis of 88 patients who underwent LASIK for treatment of hyperopia concluded that DED was particularly problematic in females and was associated with refractive regression. ${ }^{98}$

Blepharoplasty after a LASIK procedure creates an increased risk for development of severe DED. ${ }^{59}$ This is because the LASIK procedure can reduce corneal sensitivity, resulting in a decreased blink rate and subsequent reduction in tear production. Postprocedure, blepharoplasty causes transient (or infrequently, permanent) lagophthalmos, which is compensated for by an increase in blink rate. However, if the tear volume is insufficient because of a prior LASIK procedure, the increased blink rate can cause mechanical irritation. ${ }^{99}$

In the United States in 2015, women accounted for $85 \%$ of those presenting for more than 200,000 cosmetic blepharoplasty procedures. ${ }^{100}$ From a 2013 10-year retrospective medical record review of patients undergoing cosmetic blepharoplasty (892 patients, $16-83$ years of age with a mean age of 53 years), $86.1 \%$ were female and $63 \%$ underwent concurrent upper and lower blepharoplasty. Compared with an upper or lower blepharoplasty alone, the concurrent procedure was more highly associated with the percentage of patients that subsequently developed DED (31.3\% concurrent vs. $12.9 \%$ upper and $22.9 \%$ lower, chi square test $=18.1$, $p<0.001){ }^{101}$

Botulinum toxin type A (BTX-A) injections ${ }^{102}$ are used in ophthalmology to improve a number of conditions, including DED. BTX-A injections into the periorbital area, such as the orbicularis muscle, have been used successfully to treat dry eye by reducing lacrimal drainage. ${ }^{103}$ However, repeated
BTX-A injections into lateral canthal rhytids for cosmetic effect, more commonly known as correction of crow's feet, may cause temporary dry eye due to muscle weakness that results in incomplete blinking. ${ }^{104}$ As the effect of these injections is transient, the experience of dry eye symptoms may also be transient. However, if DED is already present, or the patient has comorbidities that incur a risk for DED, the transient cause may lead to a chronic condition. ${ }^{102-104}$

Dermapigmentation of the eyelids, or cosmetic eye tattooing, can cause a destruction of the MGs due to excessive needle penetration and ink pigment migration. ${ }^{105}$ Loss of MGs in these cases reduces the lipid layer of the tear film and can lead to EDE. Topical ocular cosmetics, especially mascara and eyeliner, as well as oil-based facial creams applied near the eye, can cause changes to the tear film and its stability. Retinoids in moisturizing creams have been associated with problems in MGs. ${ }^{10}$ In a study that compared ocular comfort and OSDI scores between cosmetic users $(N=1,360$ females, median age 25 years; $83 \%$ reported wearing cosmetics $>3$ times per week [mascara most common]) and nonusers, OSDI scores were found to be similar $(p=0.083)^{106}$ When cosmetics were not used by habitual users, the perception of ocular comfort increased $(p<0.001)$.

Prescribed medications can also contribute to the development of dry eye. ${ }^{59}$ These can arise from side effects, which cause systemic changes that decrease secretory fluids and result in dryness of mucous membranes (e.g., dry mouth, dry eyes), or induce local changes in eye function (e.g., reduction in production of tear film components, induction of inflammation, and/or swelling of ocular tissues). ${ }^{59}$ Active ingredients or inactive ingredients (i.e., preservatives) of topical ophthalmic medications may cause or aggravate eye dryness, irritating ocular tissues or destabilizing the tear film.

While preservative-free preparations of ophthalmic products are commonly available, many ophthalmic preparations contain preservatives to prevent microbial proliferation, deciphering the contribution of the active versus inactive ingredient as it relates to DED can be difficult. The beta blocker timolol induces tear film instability and disrupts corneal 
barrier function, and the antihistamine olopatadine contributes to reduced tear volume. ${ }^{108}$ Preservatives that may contribute to dry eye symptoms include benzalkonium chloride (BAK); benzethonium chloride and cetyl pyridinium chloride; benzyl bromide; benzyl, cetyl, and phenylethyl alcohols; chlorobutanol; edetate disodium (EDTA); phenylmercury nitrate, acetate, and borate; thimerosal; merthiolate; polymyxin B sulfate; chlorhexidine; methyl and propyl parabens; quaternary ammonium chloride; sodium benzoate and propionate; and sorbic acid. ${ }^{109}$ The most widely used ocular administration preservative, BAK, has been shown to have cytotoxic and proinflammatory effects on the eye, and its detergent properties disrupt the tear film. ${ }^{59}$

In the Beaver Dam Eye Study cohort, previous use of daily over-the-counter medications, including aspirin (odds ratio 1.18 [95\% confidence interval 0.99-1.40] $p=0.06$ ) and/or multivitamins (1.37 [1.08-1.74]; $p<0.005)$, were nearly or statistically significantly associated with age- and sex-adjusted prevalence of dry eye. ${ }^{3}$ Among the more than dozen classes of medications identified that provide increased risks of DED, several of these classes are specific to women (e.g., hormone replacement therapy), and/or are used significantly more by women than by men across age groups (antihistamines, anxiolytics, antidepressants, antipsychotics). ${ }^{6,59,107,110}$ Examples of specific systemic medications associated with DED are listed in Table 4.

The association of DED and hormone treatments in women is not well understood but may involve adverse effects of increased ocular levels of estrogen on MGs or production of tear film components. In the WHS analysis, postmenopausal HT increased DED risk by $\sim 70 \%$ for estrogen users and $\sim 30 \%$ for estrogen+progesterone/progestin users. ${ }^{12}$ A cross-sectional study of 360 postmenopausal women investigating the effect of HT on DED showed significant differences in increased DED severity between the following groups: HT versus no HT $(p<0.0001)$; HT dosage level $>1 \mathrm{mg} /$ day versus $<1 \mathrm{mg} /$ day $(p<0.0001)$; and HT duration of at least 12,36 , or 48 months $(p<0.0001) .{ }^{111}$ Oral contraceptive pill (OCP) use in premenopausal women $(n=52 \mathrm{OCP}, n=45$ non-OCP, mean age,
$26.0 \pm 3.7$ years $)$, resulted in higher SANDE scores $(p<0.01)$ and the combination of OCP and recent contact lens wear were associated with higher SANDE $(p<0.001)$ and OSDI scores $(p=0.015) .^{112}$

Serotonin/norepinephrine reuptake inhibitors (SNRIs), used to treat depression, have known anticholinergic adverse effects, including decreased lacrimal secretion, that increase the risk of dry eye. ${ }^{110}$ Selective serotonin reuptake inhibitors (SSRIs), an alternative class of medication for treatment of depression, do not adversely affect the cholinergic system.

However, in an investigation of tear film volume (classified as $>5$ or $\leq 5 \mathrm{~mm}$ by the Schirmer test) with antidepressant use ( $\geq 4$ weeks), duloxetine (SNRI), venlafaxine (SNRI), and escitalopram (SSRI) significantly reduced tear film volume $(p<0.001)$ compared with control patients not on antidepressants. This finding suggests that SSRIs may impact tear film volume through a mechanism outside the cholinergic system. Patients using SSRIs had lower wetting measurements compared with those on SNRIs $(p<0.05)$. However, both SNRIs and SSRIs may contribute to dry eye. ${ }^{110}$ In the SSRI group, 10 patients (19.8\% of 54 eyes) had dry eye, and in the SNRI group 19 patients (35\% of 54 eyes) had dry eye. The tricyclic antidepressants amitriptyline and thioridazine for schizophrenia also have anticholinergic effects that increase the risk for DED. ${ }^{113}$

\section{Gender Differences in Health-Related Quality of Life}

Indicators associated with overall physical and mental health include adequate sleep; stable moods; balanced nutrition; and minimal stress, anxiety, and depression. ${ }^{32,114-117}$ For many of these indicators, women fare poorer in selfreports than men, ${ }^{19}$ and among DED patients women report worse health-related quality of life and perceived health than men. 6,9,21 As compared with men, women report a greater impact of DED on visual quality indicators, including poor vision, blurred vision, and fluctuating/unstable vision, as well as sustained visual attention tasks, including reading, night driving, television viewing, and computer/monitor work. ${ }^{6}$

Table 4. Selected and Illustrative Systemic Medications Associated with Dry Eye Disease (adapted ${ }^{135}$ )

\begin{tabular}{|c|c|}
\hline $\begin{array}{l}\text { Medication } \\
\text { type }\end{array}$ & $\begin{array}{c}\text { Medications with reported side effect categories, including burning sensation, } \\
\text { keratoconjunctivitis sicca, decreased lacrimation, meibomian gland changes, sicca-ocular, } \\
\text { Stevens-Johnson syndrome }\end{array}$ \\
\hline Antidepressants & $\begin{array}{l}\text { Agomelatine, Amitriptyline, Bupropion, Clomipramine, Citalopram, Desipramine, Doxepin, } \\
\text { Duloxetine, Fluoxetine, Fluvoxamine, Imipramine, Mianserin, Mirtazapine, Nortriptyline, } \\
\text { Paroxetine, Reboxetine, Sertraline, Tianeptine, Trazodone, Venlafaxine }\end{array}$ \\
\hline Antihistamines & $\begin{array}{l}\text { Azelastine, Brompheniramine*, Carbinoxamine*, Cetirizine*, Chlorpheniramine*, Clemastine*, } \\
\text { Cyproheptadine*, Desloratadine*, Dexchlorpheniramine*, Diphenhydramine*, Doxylamine*, } \\
\text { Epinastine, Fexofenadine*, Hydroxyzine, Ketotifen, Loratadine*, Olopatadine, Promethazine, } \\
\text { Pseudoephedrine, Tripelennamine*, Triprolidine* }\end{array}$ \\
\hline Antipsychotics & $\begin{array}{l}\text { Aiprasidone, Aripiprazole, Brompheniramine, Carbinoxamine, Chlorpheniramine, Chlorpromazine, } \\
\text { Clemastine, Clozapine, Cyproheptadine, Dexchlorpheniramine, Fluphenazine, Haloperidol, Lithium } \\
\text { carbonate, Olanzapine, Perphenazine, Promethazine, Quetiapine, Risperidone, Sulpiride, } \\
\text { Thiethylperazine, Thioridazine Thiothixene, Trifluoperazine }\end{array}$ \\
\hline Anxiolytics & Alprazolam*, Diazepam*, Eszopiclone, Lorazepam*, Zolpidem, Zopiclone \\
\hline Hormonal & $\begin{array}{l}\text { Alfuzosin, Doxazosin, Finasteride*, Leuprorelin*, Tamsulosin, Terazosin, Estrogen/progesterone, } \\
\text { Medroxyprogesterone }\end{array}$ \\
\hline Neurotoxins & Botulinum $\mathrm{A}^{*}$ or $\mathrm{B}$ \\
\hline
\end{tabular}

"Associated" specifically refers to systemic medications causing, contributing to, or aggravating dry eye.
*Drugs identified with a causative relationship to dry eye symptoms as described by Fraunfelder et al. ${ }^{135}$ 
A study of 890 women 30-69 years of age found that Pittsburgh Sleep Quality Index scores (mean \pm SD) were worse in patients with DED $(6.1 \pm 2.9)$ versus without DED $(4.9 \pm 2.7) ; p=0.003$. $^{17}$ The Hospital Anxiety and Depression Scores (mean $\pm \mathrm{SD}$ ) in the same study were worse in patients with DED 30-45 years of age $(13.2 \pm 6.0)$ than in those without DED $(9.7 \pm 6.0) ; p=0.02 .^{17}$

A 2010-2011 analysis of the Korea National Health and Nutrition Examination Survey (a population-based crosssectional study) in 6,655 females was carried out to look at the association between DED signs and symptoms and depressive symptoms. ${ }^{16}$ Across all respondents, $20 \%$ experienced DED symptoms, and DED prevalence from a confirmed diagnosis was $12.3 \%$. Also, a DED diagnosis was associated with greater odds of experiencing anxiety and/or depression (odds ratio [OR], 1.5; 95\% CI: 1.1-2.0), depressive mood (OR 1.5; 95\% CI: 1.1-2.0), severe psychological stress (OR 2.5; 95\% CI: 1.6-4.0), and of having had prior psychological counseling (OR 1.8; 95\% CI: 1.0-3.1).

\section{Gender Differences in Care-seeking Behaviors and Health Care Service Utilization}

Women have been found to interact more and differently with the health care system than men ${ }^{118}$ in ways that offer opportunities for earlier detection, referral, preventative treatment, and/or diagnosis in the treatment of DED. Based on a survey of 1,518 women and 581 men who previously participated in the WHS ${ }^{12}$ and PHS I and II, ${ }^{39}$ more women than men reported using traditional DED therapies (level 1). ${ }^{6}$ These included artificial tears $(82.8 \%$ vs. $62.6 \% ; p<0.0001)$, lubricating eye ointments $(19.2 \%$ vs. $11.7 \% ; p<0.0001)$, and hot compresses $(14.3 \%$ vs. $10.7 \% ; p<0.02){ }^{6}$ This is also true of the next tier of DED therapies (level 2); omega-3 fatty acids $(18.6 \%$ vs. $9.6 \% ; p=0.0006)$, cyclosporine eye drops $(13.4 \%$ vs. $6.4 \% ; p<0.0001)$, and punctal occlusion $(15.0 \%$ vs. $9.1 \%$; $p=0.005)^{6}$

Overall, the same level of general satisfaction with DED treatments was reported, however, compared with men, women reported greater dissatisfaction with side effects of DED therapies and the amount of time for the treatment to alleviate symptoms. In an alternate model, dissatisfaction with the convenience of treatment use as instructed was less in women than in men (OR 0.74; 95\% CI: 0.58-0.95). ${ }^{6}$

Overall, compared with men, women may try a more diverse set of treatments, including nutritional supplements and other over-the-counter therapies. ${ }^{119,120}$ Tear film homeostasis has been found to be dependent on adequate nutrition, particularly sufficient intake of protein and vitamin A. ${ }^{121} \mathrm{~A}$ low-fat diet, rich in antioxidants and omega fatty acids, has previously been shown to benefit both the tear film and ocular surface, ${ }^{122,123}$ leading many clinicians to recommend omega3 fatty acids to patients to alleviate DED symptoms.

Schaumberg et al. found that women use omega-3 fatty acids for the treatment of their DED symptoms significantly more often than men. ${ }^{6}$ A 2013 multicenter double-masked placebo-controlled clinical trial of 38 postmenopausal women with moderate-to-severe DED was conducted to measure the effect of supplementation with gamma-linolenic acid (GLA) and omega-3 (n-3) polyunsaturated fatty acids (PUFAs) on DED signs and symptoms. ${ }^{124}$ A change from baseline to 24 weeks in OSDI scores of women taking supplements $(N=19)$ were significantly improved compared with women taking placebo $(N=19)$; OSDI score $21 \pm 4$ vs. $34 \pm 5$; $p=0.05$. Also at 24 weeks, conjunctival impression cytology measures of CD11c integrin and HLA-DR expression, both DED diseaserelevant inflammatory mediators, showed increases of $>30 \%$ for placebo compared with supplement treatment $(p=0.001)$. However, no differences between placebo and supplement treatment cohorts were found for tear production, tear breakup time, or corneal or conjunctival staining. ${ }^{124}$

In the recently published Dry Eye Assessment and Management (DREAM) study, a large randomized clinical trial, 535 DED patients with moderate-to-severe DED were assigned 2:1 to receive "active" or placebo supplements over 12 months. ${ }^{125}$ The active supplements contained $400 \mathrm{mg}$ of eicosapentaenoic acid (EPA) and $200 \mathrm{mg}$ of docosahexaenoic acid (DHA), both omega-3 (n-3) fatty acids, taken five times daily, for a total dose of $3,000 \mathrm{mg}$. Placebo capsules contained $1,000 \mathrm{mg}$ of refined olive oil made up of $68 \%$ oleic acid (n-9), $13 \%$ palmitic acid (saturated), and $11 \%$ linoleic acid (n-6). Both active and placebo capsules contained an antioxidant; $3 \mathrm{mg}$ of vitamin E (alpha-tocopherol). During the trial, patients were allowed to continue their current treatments for DED. While the data in this study were not stratified by sex/gender or age, females comprised $>80 \%$ of the omega- 3 and placebo cohorts and the mean age was 58 years. ${ }^{125}$

After 12 months of treatment, signs and symptoms of DED improved significantly in both the active and placebo cohorts, with $53 \%$ of the active cohort and $57 \%$ of the placebo cohort reporting less use of additional treatments for their dry eye. Mean OSDI scores decreased by $13.9 \pm 15.6$ points for the active group and by $12.5 \pm 18.2$ points for the placebo group; however, the difference between groups was not significant $(p=0.40)$. Based on between-group differences in changes from baseline to 12 months in OSDI score, corneal staining, tear break-up time, and Schirmer's test, the omega-3 supplement did not show additional benefit compared with placebo. The olive oil placebo capsules used in this study, which predominantly contained oleic acid, an omega-9 PUFA, was not expected to have an effect on the signs and symptoms of DED. ${ }^{125}$

Methodological difficulties of the placebo effect in DED clinical trials of topical treatments have been previously reported. ${ }^{126}$ A combined analysis of the placebo arms of three clinical trials of diquafosol treatment for DED carried out in Japan, comprised of 205 DED patients $(82.4 \%$ female with a mean \pm SD age of $54.4 \pm 17.9$ ) found high baseline scores, indicating increased DED severity, and aging to be predictive of the magnitude of placebo response. ${ }^{126}$

\section{Conclusions}

DED can be a complex and time-consuming condition to manage, and some individuals with DED experience refractory symptoms. It is well supported that the sex and gender differences between women and men, especially as they age, contribute to differences in the prevalence and severity of DED.

In this study, we have reviewed sex and gender differences in DED causes, clinical sign presentation, patient experience of symptoms, and-perhaps most relevantly-differences in treatment response and efficacy. While some of these differences are biological, with sex-specific hormones having a great effect on DED etiology, there are also comorbidities and gender-based factors that contribute to DED risk in women. 
Because there is a strong association of autoimmune diseases and DED, especially those that primarily affect women, both systemic and overall effects of DED need to be assessed in treatment options of DED and comorbidities. The high burden of comorbidities women with DED face suggests they would benefit from an interdisciplinary approach to DED treatment. Women are diagnosed with DED at earlier ages, and progression to severe forms of the disease is more prevalent in women than men. Thus, earlier diagnosis of DED in women may result in a significant improvement in their quality of life.

In light of the many women's health topics raised here with associations to DED, opportunities for educating women and health care providers on this highly prevalent and burdensome disease should be maximized; and when dry eye is suspected, referral to an optometrist or ophthalmologist for a dry eye examination is warranted.

\section{Acknowledgments}

This review was funded by Shire Development LLC. The authors thank Shirley Louise-May of Excel Scientific Solutions, who provided medical writing assistance, funded by Shire PLC.

\section{Author Contributions}

All authors participated in the development of the intellectual content, provided important critique for each revision, and gave approval for the final version of this article.

\section{Author Disclosure Statement}

C.M.-Consultant to Alcon, Allergan, Bausch and Lomb, Bruder, Checked-Up, i-Optics, Johnson \& Johnson, Lenstec, Marco, Ocular Therapeutix, Inc., Omeros, PRN, Progressive Tech Training, Shire, SUN, TearLab, and Zeiss; M.M.Consultant to Alcon, Allergan, Bausch and Lomb, Bruder, Johnson and Johnson, Sun, Shire, Omeros, TearLab, BioSyntrix, OCUSOFT, ORCA Surgical, BlephEx, BioTissue, and OCULUS USA; P.K.G.-Consultant to Alcon, Allergan, Aurea, BioTissue, Johnson \& Johnson, Kala, NovaBay, Novartis, Ocular Science, Shire, TearLab, TearScience, and Zeiss; S.M.-Alcon, Allergan, INNOVA Medical Ophthalmics, Novartis, Optos, and Shire; K.K.N.-Consultant for Alcon, Allergan, Bausch and Lomb, Bruder, Hovione, ScienceBased Health, Shire/SarCode, SightSciences, and SUN/Insite. Research support: Alcon, Allergan, Bruder, Johnson \& Johnson, Kala, National Institutes of Health, Oculus, Shire, and TearScience; K.D.-Consultant for Alcon, Allergan, Bausch and Lomb, Johnson \& Johnson, NovaBay, Omeros, Shire, SUN, and TearLab.

\section{References}

1. Craig JP, Nichols KK, Akpek EK, et al. TFOS DEWS II Definition and Classification Report. Ocul Surf 2017;15: 276-283.

2. Herrero-Vanrell R, Peral A. [International Dry Eye Workshop (DEWS). Update of the disease]. Arch Soc Esp Oftalmol 2007;82:733-734.

3. Moss SE, Klein R, Klein BE. Prevalence of and risk factors for dry eye syndrome. Arch Ophthalmol 2000;118: 1264-1268.
4. Viso E, Rodriguez-Ares MT, Gude F. Prevalence of and associated factors for dry eye in a Spanish adult population (the Salnes Eye Study). Ophthalmic Epidemiol 2009; $16: 15-21$.

5. Galor A, Feuer W, Lee DJ, et al. Prevalence and risk factors of dry eye syndrome in a United States Veterans Affairs population. Am J Ophthalmol 2011;152:377384.e372.

6. Schaumberg DA, Uchino M, Christen WG, Semba RD, Buring JE, Li JZ. Patient reported differences in dry eye disease between men and women: Impact, management, and patient satisfaction. PLoS One 2013;8:e76121.

7. Paulsen AJ, Cruickshanks KJ, Fischer ME, et al. Dry eye in the Beaver Dam Offspring Study: Prevalence, risk factors, and health-related quality of life. Am J Ophthalmol 2014; 157:799-806.

8. Orucoglu F, Akman M, Onal S. Analysis of age, refractive error and gender related changes of the cornea and the anterior segment of the eye with Scheimpflug imaging. Cont Lens Anterior Eye 2015;38:345-350.

9. McDonald M, Bitton E, Hauser W, Karpecki P, O'Brien T. Women and dry eye-Shining a light on this essential dry eye disease segment. In: Tears T, ed. Review of Ophthalmol., Jobson Medical Information, LLC. Oct, 2016:1-7.

10. Sullivan DA, Rocha EM, Aragona P, et al. TFOS DEWS II sex, gender, and hormones report. Ocul Surf 2017;15: 284-333.

11. Stapleton F, Alves M, Bunya VY, et al. TFOS DEWS II Epidemiology Report. Ocul Surf 2017;15:334-365.

12. Schaumberg DA, Sullivan DA, Buring JE, Dana MR. Prevalence of dry eye syndrome among US women. Am J Ophthalmol 2003;136:318-326.

13. Baudouin C. [A new approach for better comprehension of diseases of the ocular surface]. J Fr Ophtalmol 2007;30: 239-246.

14. Uchino M, Schaumberg DA. Dry eye disease: Impact on quality of life and vision. Curr Ophthalmol Rep 2013;1: 51-57.

15. Ahn JM, Lee SH, Rim TH, et al. Prevalence of and risk factors associated with dry eye: The Korea National Health and Nutrition Examination Survey 2010-2011. Am J Ophthalmol 2014;158:1205-1214.e1207.

16. Na KS, Han K, Park YG, Na C, Joo CK. Depression, stress, quality of life, and dry eye disease in Korean women: A population-based study. Cornea 2015;34:733-738.

17. Ayaki M, Kawashima M, Negishi K, Kishimoto T, Mimura M, Tsubota K. Sleep and mood disorders in women with dry eye disease. Sci Rep 2016;6:35276.

18. Crane AM, Levitt RC, Felix ER, Sarantopoulos KD, McClellan AL, Galor A. Patients with more severe symptoms of neuropathic ocular pain report more frequent and severe chronic overlapping pain conditions and psychiatric disease. Br J Ophthalmol 2017;101:227-231.

19. Zajacova A, Huzurbazar S, Todd M. Gender and the structure of self-rated health across the adult life span. Soc Sci Med 2017;187:58-66.

20. Gharib SD, Manson JA. Women's health care: One size does not fit all. J Gen Intern Med 2000;15:68-69.

21. Bron A, Tomlinson A, Foulks G, et al. Rethinking dry eye disease: A perspective on clinical implications. Ocular Surf 2014;12:S1-S31.

22. Downie LE, Keller PR. A pragmatic approach to dry eye diagnosis: Evidence into practice. Optom Vis Sci 2015;92: 1189-1197. 
23. Vehof J, Sillevis Smitt-Kamminga N, Nibourg SA, Hammond CJ. Predictors of discordance between symptoms and signs in dry eye disease. Ophthalmology 2017;124:280-286.

24. Baudouin C. The pathology of dry eye. Surv Ophthalmol 2001;45:S211-S220.

25. Rodman J. When autoimmune disease initiates dry eye. Review of Optometry. 2011. https://www.reviewsce.com/ ce/when-autoimmune-disease-initiates-dry-eye. Accessed January 1, 2019.

26. Stern ME, Schaumburg CS, Siemasko KF, et al. Autoantibodies contribute to the immunopathogenesis of experimental dry eye disease. Invest Ophthalmol Vis Sci 2012;53:2062-2075.

27. Zhang X, Volpe EA, Gandhi NB, et al. NK cells promote Th-17 mediated corneal barrier disruption in dry eye. PLoS One 2012; 7:e36822.

28. Chen Y, Chauhan SK, Lee HS, Saban DR, Dana R. Chronic dry eye disease is principally mediated by effector memory Th17 cells. Mucosal Immunol 2014;7:38-45.

29. Generali E, Cantarini L, Selmi C. Ocular involvement in systemic autoimmune diseases. Clin Rev Allergy Immunol 2015;49:263-270.

30. Guzman M, Keitelman I, Sabbione F, Trevani AS, Giordano MN, Galletti JG. Desiccating stress-induced disruption of ocular surface immune tolerance drives dry eye disease. Clin Exp Immunol 2016;184:248-256.

31. Pflugfelder SC, de Paiva CS. The pathophysiology of dry eye disease: What we know and future directions for research. Ophthalmology 2017;124:S4-S13.

32. Farrand KF, Fridman M, Stillman IO, Schaumberg DA. Prevalence of diagnosed dry eye disease in the United States among adults aged 18 years and older. Am J Ophthalmol 2017;182:90-98.

33. Bron AJ, de Paiva CS, Chauhan SK, et al. TFOS DEWS II pathophysiology report. Ocul Surf 2017;15:438-510.

34. Willcox MDP, Argueso P, Georgiev GA, et al. TFOS DEWS II tear film report. Ocul Surf 2017;15:366-403.

35. Eye anatomy. 2017. Available at: http://teaching.pharmacy .umn.edu/courses/eyeAP/Eye_Anatomy/CoatsoftheEye/Tear FilmStructure.htm Accessed September 17, 2017.

36. Gilbard JP. Dry eye and blepharitis: Approaching the patient with chronic eye irritation. Geriatrics 2009;64:22-26.

37. Yazdani C, McLaughlin T, Smeeding JE, Walt J. Prevalence of treated dry eye disease in a managed care population. Clin Ther 2001;23:1672-1682.

38. Malet F, Le Goff M, Colin J, et al. Dry eye disease in French elderly subjects: The Alienor Study. Acta Ophthalmol 2014;92:e429-e436.

39. Schaumberg DA, Dana R, Buring JE, Sullivan DA. Prevalence of dry eye disease among US men: Estimates from the Physicians' Health Studies. Arch Ophthalmol 2009;127:763-768.

40. Schiffman RM, Christianson MD, Jacobsen G, Hirsch JD, Reis BL. Reliability and validity of the Ocular Surface Disease Index. Arch Ophthalmol 2000;118:615-621.

41. Gulati A, Sullivan R, Buring JE, Sullivan DA, Dana R, Schaumberg DA. Validation and repeatability of a short questionnaire for dry eye syndrome. Am J Ophthalmol 2006;142:125-131.

42. Bradley J, Guerin A, Pivneva I, et al. Estimates of incidence and prevalence of dry eye disease across age groups in the US using data from a large healthcare system. American Academy of Optometry 2016. Anaheim, CA: American Academy of Optometry, 2016.
43. Institute of Medicine. Exploring the Biological Contributions to Human Health: Does Sex Matter? Washington, DC: The National Academies Press, 2001.

44. Suzuki T, Richards SM, Liu S, Jensen RV, Sullivan DA. Influence of sex on gene expression in human corneal epithelial cells. Mol Vis 2009;15:2554-2569.

45. Toshino A, Shiraishi A, Zhang W, Suzuki A, Kodama T, Ohashi Y. Expression of keratinocyte transglutaminase in cornea of vitamin A-deficient rats. Curr Eye Res 2005;30: 731-739.

46. Hirai N, Kawasaki S, Tanioka H, et al. Pathological keratinisation in the conjunctival epithelium of Sjogren's syndrome. Exp Eye Res 2006;82:371-378.

47. Nakamura T, Nishida K, Dota A, Matsuki M, Yamanishi $\mathrm{K}$, Kinoshita S. Elevated expression of transglutaminase 1 and keratinization-related proteins in conjunctiva in severe ocular surface disease. Invest Ophthalmol Vis Sci 2001;42:549-556.

48. Tong L, Png E, Lan W, Petznick A. Recent advances: Transglutaminase in ocular health and pathological processes. J Clinic Experiment Ophthalmol 2011;S2:002.

49. Duarte MC, Pinto NT, Moreira H, Moreira AT, Wasilewski D. Total testosterone level in postmenopausal women with dry eye. Arq Bras Oftalmol 2007;70:465469.

50. Gagliano C, Caruso S, Napolitano G, et al. Low levels of 17-beta-oestradiol, oestrone and testosterone correlate with severe evaporative dysfunctional tear syndrome in postmenopausal women: A case-control study. Br J Ophthalmol 2014;98:371-376.

51. Sriprasert I, Warren DW, Mircheff AK, Stanczyk FZ. Dry eye in postmenopausal women: A hormonal disorder. Menopause 2016;23:343-351.

52. Ablamowicz AF, Nichols JJ, Nichols KK. Association between serum levels of testosterone and estradiol with meibomian gland assessments in postmenopausal women. Invest Ophthalmol Vis Sci 2016;57:295-300.

53. Pieragostino D, Agnifili L, Cicalini I, et al. Tear film steroid profiling in dry eye disease by liquid chromatography tandem mass spectrometry. Int J Mol Sci 2017;18: pii:E1349.

54. Viso E, Rodriguez-Ares MT, Abelenda D, Oubina B, Gude F. Prevalence of asymptomatic and symptomatic meibomian gland dysfunction in the general population of Spain. Invest Ophthalmol Vis Sci 2012;53:2601-2606.

55. Bukhari AA, Basheer NA, Joharjy HI. Age, gender, and interracial variability of normal lacrimal gland volume using MRI. Ophthal Plast Reconstr Surg 2014;30:388391.

56. Connor C, Flockencier L, Hall C. The influence of gender on the ocular surface. J Am Optom Assoc 1999;70:182186.

57. Cavdar E, Ozkaya A, Alkin Z, Ozkaya HM, Babayigit MA. Changes in tear film, corneal topography, and refractive status in premenopausal women during menstrual cycle. Cont Lens Anterior Eye 2014;37:209-212.

58. Versura P, Fresina M, Campos EC. Ocular surface changes over the menstrual cycle in women with and without dry eye. Gynecol Endocrinol 2007;23:385-390.

59. Gomes JAP, Azar DT, Baudouin C, et al. TFOS DEWS II iatrogenic report. Ocul Surf 2017;15:511-538.

60. Ortona E, Pierdominici M, Maselli A, Veroni C, Aloisi F, Shoenfeld Y. Sex-based differences in autoimmune diseases. Ann Ist Super Sanita 2016;52:205-212. 
61. Fortune MD, Guo H, Burren O, et al. Statistical colocalization of genetic risk variants for related autoimmune diseases in the context of common controls. Nat Genet 2015;47:839-846.

62. Chang ALS, Raber I, Xu J, et al. Assessment of the genetic basis of rosacea by genome-wide association study. J Invest Dermatol 2015;135:1548-1555.

63. van Vollenhoven RF. Sex differences in rheumatoid arthritis: More than meets the eye... BMC Med 2009;7:12.

64. Kramer JM. Early events in Sjogren's Syndrome pathogenesis: The importance of innate immunity in disease initiation. Cytokine 2014;67:92-101.

65. Forsblad-d'Elia H, Carlsten H, Labrie F, Konttinen YT, Ohlsson C. Low serum levels of sex steroids are associated with disease characteristics in primary Sjogren's syndrome; supplementation with dehydroepiandrosterone restores the concentrations. J Clin Endocrinol Metab 2009;94:2044-2051.

66. Silpa-archa S, Lee JJ, Foster CS. Ocular manifestations in systemic lupus erythematosus. Br J Ophthalmol 2016;100: 135-141.

67. Soo MP, Chow SK, Tan CT, Nadior N, Yeap SS, Hoh HB. The spectrum of ocular involvement in patients with systemic lupus erythematosus without ocular symptoms. Lupus 2000;9:511-514.

68. Zlatanovic G, Veselinovic D, Cekic S, Zivkovic M, Dordevic-Jocic J, Zlatanovic M. Ocular manifestation of rheumatoid arthritis-different forms and frequency. Bosn J Basic Med Sci 2010;10:323-327.

69. Patel S, Lundy D. Ocular manifestations of autimmune disease. Am Fam Physician 2002;66:991-998.

70. Gadina M. Janus kinases: An ideal target for the treatment of autoimmune diseases. J Investig Dermatol Symp Proc 2013;16:S70-S72.

71. O'Shea JJ, Kontzias A, Yamaoka K, Tanaka Y, Laurence A. Janus kinase inhibitors in autoimmune diseases. Ann Rheum Dis 2013;72 Suppl 2:ii111-ii115.

72. Vieira AC, Hofling-Lima AL, Mannis MJ. Ocular rosacea-A review. Arq Bras Oftalmol 2012;75:363-369.

73. Arman A, Demirseren D, Takmaz T. Treatment of ocular rosacea: Comparative study of topical cyclosporine and oral doxycycline. Int J Ophthalmol 2015;8:544-549.

74. Allergan. Restasis: Full prescribing information. In: Allergan, ed. Allergan. Irvine, CA: Allergan, 2016.

75. Kellogg Eye Center MM. Thyroid Eye Disease (TED or Graves Eye Disease). 2017. Available at: www.umkelloggeye .org/conditions-treatments/thyroid-eye-disease Accessed August 28, 2017.

76. Smith TJ, Hegedus L. Graves' disease. N Engl J Med 2016;375:1552-1565.

77. Shtein RM, Harper DE, Pallazola V, et al. Discordant dry eye disease (An American Ophthalmological Society Thesis). Trans Am Ophthalmol Soc 2016;114:T4.

78. Galor A, Covington D, Levitt AE, et al. Neuropathic ocular pain due to dry eye is associated with multiple comorbid chronic pain syndromes. J Pain 2016;17:310-318.

79. Rosenthal P, Borsook D. Ocular neuropathic pain. Br J Ophthalmol 2016;100:128-134.

80. Belmonte C, Nichols JJ, Cox SM, et al. TFOS DEWS II pain and sensation report. Ocul Surf 2017;15:404-437.

81. Vehof J, Kozareva D, Hysi PG, Hammond CJ. Prevalence and risk factors of dry eye disease in a British female cohort. Br J Ophthalmol 2014;98:1712-1717.
82. Vehof J, Sillevis Smitt-Kamminga N, Kozareva D, Nibourg SA, Hammond CJ. Clinical characteristics of dry eye patients with chronic pain syndromes. Am J Ophthalmol 2016;166:203-204.

83. Wolffsohn JS, Arita R, Chalmers R, et al. TFOS DEWS II Diagnostic Methodology report. Ocul Surf 2017;15:539574.

84. Vehof J, Wang B, Kozareva D, Hysi PG, Snieder H, Hammond CJ. The heritability of dry eye disease in a female twin cohort. Invest Ophthalmol Vis Sci 2014;55: 7278-7283.

85. Shtein R, Williams D, Clauw D. Dry eye disease and fibromyalgia. IOVS 2011;52:3856.

86. Vehof J, Sillevis Smitt-Kamminga N, Nibourg SA, Hammond CJ. Sex differences in clinical characteristics of dry eye disease. Ocul Surf 2018;16:242-248.

87. Nichols KK, Nichols JJ, Mitchell GL. The lack of association between signs and symptoms in patients with dry eye disease. Cornea 2004;23:762-770.

88. Novack GD, Asbell P, Barabino S, et al. TFOS DEWS II Clinical Trial Design Report. Ocul Surf 2017;15:629-649.

89. Healthy Contact Lens Wear and Care. 2017. Available at: www.cdc.gov/contactlenses/fast-facts.html\#two Accessed October 10, 2017.

90. American Optometric Association. 2017. Available at: www.aoa.org/patients-and-public/caring-for-your-vision/ contact-lenses/facts-and-stats. Accessed October 10, 2017.

91. Kastelan S, Lukenda A, Salopek-Rabatic J, Pavan J, Gotovac M. Dry eye symptoms and signs in long-term contact lens wearers. Coll Antropol 2013;37 Suppl 1:199-203.

92. Doughty MJ, Fonn D, Richter D, Simpson T, Caffery B, Gordon K. A patient questionnaire approach to estimating the prevalence of dry eye symptoms in patients presenting to optometric practices across Canada. Optom Vis Sci 1997;74:624-631.

93. González-Méijome J, Parafita M, Yebra-Pimentel E, Almeida J. Symptoms in a population of contact lens and noncontact lens wearers under different environmental conditions. Optom Vis Sci 2007;84:296-302.

94. Richdale K, Sinnott LT, Skadahl E, Nichols JJ. Frequency of and factors associated with contact lens dissatisfaction and discontinuation. Cornea 2007;26:168-174.

95. Nichols JJ, Willcox MD, Bron AJ, et al. The TFOS International Workshop on Contact Lens Discomfort: Executive summary. Invest Ophthalmol Vis Sci 2013;54: TFOS7-TFOS13.

96. Lin MC, Yeh TN. Mechanical complications induced by silicone hydrogel contact lenses. Eye Contact Lens 2013; 39:115-124.

97. Cumberland PM, Chianca A, Rahi JS; UK Biobank Eyes \& Vision Consortium. Laser refractive surgery in the UK Biobank study: Frequency, distribution by sociodemographic factors, and general health, happiness, and social participation outcomes. J Cataract Refract Surg 2015;41:2466-2475.

98. Albietz J, Lenton L, McLennan S. Effect of laser in situ keratomileusis for hyperopia on tear film and ocular surface. J Refract Surg 2002;18:113-123.

99. Mack WP. Blepharoplasty complications. Facial Plast Surg 2012;28:273-287.

100. Plastic Surgery Statistics Report. American Society of Plastic Surgeons. 2015. Available at: www.plasticsurgery.org/ documents/News/Statistics/2015/plastic-surgery-statisticsfull-report-2015.pdf Accessed October 10, 2017. 
101. Prischmann J, Sufyan A, Ting JY, Ruffin C, Perkins SW. Dry eye symptoms and chemosis following blepharoplasty: A 10-year retrospective review of 892 cases in a single-surgeon series. JAMA Facial Plast Surg 2013;15: 39-46.

102. Dutton J, Fowler A. Botulinum toxin in ophthalmology. Surv Ophthalmol 2007;52:13-31.

103. Sahlin S, Chen E, Kaugesaar T, Almqvist H, Kjellberg K, Lennerstrand G. Effect of eyelid botulinum toxin injection on lacrimal drainage. Am J Ophthalmol 2000;129:481486.

104. Ozgur OK, Murariu D, Parsa AA, Parsa FD. Dry eye syndrome due to botulinum toxin type-A injection: Guideline for prevention. Hawaii J Med Public Health 2012;71:120 123.

105. Lee Y, Kinm J, Hyon J, Wee W, Shin Y. Eyelid tattooing induces meibomian gland loss and tear film instability. Cornea 2015;34:750-755.

106. Ng A, Evans K, North R, Purslow C. Eye cosmetic usage and associated ocular comfort. Ophthalmic Physiol Opt 2012;32:501-507.

107. Wong J, Lan W, Ong LM, Tong L. Non-hormonal systemic medications and dry eye. Ocul Surf 2011;9:212226.

108. Ishibashi T, Yokoi N, Kinoshita S. Comparison of the short-term effects on the human corneal surface of topical timolol maleate with and without benzalkonium chloride. J Glaucoma 2003;12:486-490.

109. Herrero Vanrell R. [Preservatives in ophthalmic formulations: An overview]. Arch Soc Esp Oftalmol 2007;82: 531-532.

110. Kocer E, Kocer A, Ozsutcu M, Dursun AE, Kirpinar I. Dry eye related to commonly used new antidepressants. J Clin Psychopharmacol 2015;35:411-413.

111. AlAwlaqi A, Hammadeh M. Examining the relationship between hormone therapy and dry-eye syndrome in postmenopausal women: A cross-sectional comparison study. Menopause 2016;23:550-555.

112. Chen S, Massaro-Giordano G, Pistilli M, Schreiber C, Bunya V. Tear osmolarity and dry eye symptoms in women using oral contraception and contact lenses. Cornea 2013;32:423-428.

113. Wen W, Wu Y, Chen Y, et al. Dry eye disease in patients with depressive and anxiety disorders in Shanghai. Cornea 2012;31:686-692.

114. Caetano SC, Silva CM, Vettore MV. Gender differences in the association of perceived social support and social network with self-rated health status among older adults: A population-based study in Brazil. BMC Geriatrics 2013; 13:122.

115. Rohlfsen LS, Jacobs Kronenfeld J. Gender differences in trajectories of self-rated health in middle and old age: An examination of differential exposure and differential vulnerability. J Aging Health 2014;26:637-662.

116. Campos AC, Albala C, Lera L, Sanchez H, Vargas AM, Ferreira e Ferreira E. Gender differences in predictors of self-rated health among older adults in Brazil and Chile. BMC Public Health 2015;15:365.

117. Bora JK, Saikia N. Gender differentials in self-rated health and self-reported disability among adults in India. PLoS One 2015;10:e0141953.

118. Bertakis KD, Azari R, Helms LJ, Callahan EJ, Robbins JA. Gender differences in the utilization of health care services. J Fam Pract 2000;49:147-152.
119. Bailey RL, Gahche JJ, Lentino CV, et al. Dietary supplement use in the United States, 2003-2006. J Nutr 2011; 141:261-266.

120. White MR, Jacobson IG, Smith B, et al. Health care utilization among complementary and alternative medicine users in a large military cohort. BMC Complement Altern Med 2011;11:27.

121. Gaby AR. Nutritional therapies for ocular disorders: Part Three. Altern Med Rev 2008;13:191-204.

122. Jalbert I. Diet, nutraceuticals and the tear film. Exp Eye Res 2013;117:138-146.

123. Galor A, Gardener H, Pouyeh B, Feuer W, Florez H. Effect of a Mediterranean dietary pattern and vitamin D levels on dry eye syndrome. Cornea 2014;33:437-441.

124. Sheppard JD, Jr., Singh R, McClellan AJ, et al. Long-term supplementation With n-6 and n-3 PUFAs improves moderate-to-severe keratoconjunctivitis sicca: A randomized double-blind clinical trial. Cornea 2013;32:1297-1304.

125. The Dry Eye Assessment and Management Study Research Group; Asbell PA, et al. n-3 Fatty acid supplementation for the treatment of dry eye disease. N Engl J Med 2018;378:1681-1690.

126. Imanaka T, Sato I, Tanaka S, Kawakami K. Predictive factors for the placebo effect in clinical trials for dry eye: A pooled analysis of three clinical trials. Br J Ophthalmol 2017;101:1471-1474.

127. Dana R, Bradley J, Guerin A, et al. Incidence and prevalence of dry eye disease across a wide range of ages: Claims Database Analysis in a Large Health Care System in the United States. Am J Ophthalmol 2019;(pending).

128. Korn BS, Kikkawa DO, Schanzlin DJ. Blepharoplasty in the post-laser in situ keratomileusis patient: Preoperative considerations to avoid dry eye syndrome. Plast Reconstr Surg 2007;119:2232-2239.

129. Ambrosio R, Jr., Tervo T, Wilson SE. LASIK-associated dry eye and neurotrophic epitheliopathy: Pathophysiology and strategies for prevention and treatment. J Refract Surg 2008;24:396-407.

130. Parker J, Tandon A, Shtein RM, et al. Management of pain with diclofenac after femtosecond-assisted laser in situ keratomileusis. J Cataract Refract Surg 2011;37:569-573.

131. Shtein RM. Post-LASIK dry eye. Expert Rev Ophthalmol 2011;6:575-582.

132. Asiedu K, Kyei S, Boampong F, Ocansey S. Symptomatic dry eye and its associated factors: A study of university undergraduate students in Ghana. Eye Contact Lens 2017; 43:262-266.

133. Askeroglu U, Alleyne B, Guyuron B. Pharmaceutical and herbal products that may contribute to dry eyes. Plast Reconstr Surg 2013;131:159-167.

134. Chew ML, Mulsant BH, Pollock BG, et al. Anticholinergic activity of 107 medications commonly used by older adults. J Am Geriatr Soc 2008;56:1333-1341.

135. Fraunfelder FT, Sciubba JJ, Mathers WD. The role of medications in causing dry eye. J Ophthalmol 2012;2012: 285851.

Address correspondence to: Cynthia Matossian, MD, FACS Matossian Eye Associates 2 Capital Way \#326 Pennington, NJ 08534

E-mail: cmatossian@matossianeye.com 